\title{
GERAÇÃO Z E AS METODOLOGIAS ATIVAS DE APRENDIZAGEM: DESAFIOS NA EDUCAÇÃO PROFISSIONAL E TECNOLÓGICA
}

\author{
Luiz Gustavo da Silva Bispo Andrade*, Niliane Cunha Aguiar, Rodrigo Bozi Ferrete, Juliane \\ dos Santos \\ *E-mail: luiz.gustavosb2016@gmail.com \\ Instituto Federal de Ciência e Tecnologia de Sergipe, Universidade Federal de Sergipe
} DOI: $10.15628 /$ rbept.2020.8575

Artigo submetido em abr/2019 e aceito em mar/2020

\section{RESUMO}

Este artigo trata das metodologias ativas como uma possibilidade educativa inovadora para a Geração Z. O estudo tem como base o levantamento bibliográfico pertinente à temática. Objetivou-se discutir as práticas de ensino dos professores denominados imigrantes digitais, direcionadas aos ditos nativos digitais e os desafios dessas inter-relações. Os resultados apontam que as metodologias ativas de aprendizagem, com o uso das tecnologias digitais se caracterizam como uma proposta de ensino dinâmica e inovadora para a Educação Profissional e Tecnológica, propiciando maior autonomia aos discentes e ampliando as possibilidades de diálogo no contexto da sala de aula.

Palavras-Chave: Metodologias Ativas. Tecnologias Digitais. Geração Z. Educação Profissional e Tecnológica.

\section{Z GENERATION AND THE ACTIVE METHODOLOGIES OF LEARNING: CHALLENGES IN VOCATIONAL AND TECHNOLOGICAL EDUCATION}

\begin{abstract}
This article deals with active methodologies as an innovative educational possibility for Generation Z. The study is based on the relevant bibliographic survey. The objective of this paper was to discuss the teaching practices of teachers called digital immigrants, directed to digital native sayings and the challenges of these interrelationships. The results show that active learning methodologies with the use of digital technologies are characterized as a dynamic and innovative teaching proposal for Vocational and Technological Education, providing greater autonomy to students and expanding the possibilities for dialogue in the classroom context.
\end{abstract}

Keywords: Active Methodologies. Digital Technologies. Generation Z. Professional and Technological Education 


\section{INTRODUÇÃO}

A sociedade tem passado por grandes transformações tecnológicas, sendo que estas inevitavelmente alteram o processo de ensino aprendizagem. As TDIC (Tecnologias Digitais da Informação e Comunicação) têm conseguido alterar o comportamento das pessoas, sendo necessário mudar também o modus operandi e a cultura da sala de aula. Dessa maneira, algumas questões problematizam esse estudo: o educador da EPT tem conseguido suprir os anseios do aluno da nova geração do ensino médio ${ }^{1}$, por exemplo, quando se utiliza somente do modo tradicional de transmitir conhecimento? $\mathrm{O}$ aluno nativo digital se sente instigado a aprender a partir da abordagem puramente tradicional? Nos propomos a discorrer sobre elas.

As técnicas de ensino têm sido questionadas e os métodos estritamente tradicionais de transmissão de informações pelos educadores não são tão viáveis, a depender da geração que os recebe. Com o auxílio da internet o aluno tem acesso à inúmeras informações, podendo aprender em qualquer lugar, a qualquer hora, e tornar-se autônomo em sua própria aprendizagem. Todavia, a partir dessa afirmação, é importante frisar que somente informação e internet não se configuram como alavanca para um aprendizado significativo, porém, tendo esses recursos de forma mais acessível e mediados pelo professor, é possível que se tenha facilitação no processo de aprendizagem através do ferramental que as tecnologias digitais oferecem.

Assim, surgem novas possibilidades que vão de encontro ao modelo majoritário de ensino tradicional, emergindo a partir de uma pedagogia problematizadora, em junção com as TDIC, na qual o discente é motivado a ter uma postura ativa, buscando autonomia, protagonismo, em vista de uma aprendizagem ativa. Acreditamos não ser possível alterar em definitivo a tradição escolar (não sendo também uma pretensão), principalmente por estarmos inseridos numa cultura maior, que é a teoria acadêmica ${ }^{2}$ de educação brasileira. De acordo com Bertrand (2001), a teoria acadêmica orienta o ensino para a cultura clássica, evitando a armadilha dos conhecimentos científicos e tecnológicos. Há aqui uma contraposição em relação às metodologias ativas de aprendizagem e ao uso das TDIC.

Existe também a possibilidade de aproveitar o que há de melhor em cada abordagem de ensino, tanto no tradicional, quanto em metodologias inovadoras, através das novas tecnologias. Essa mescla podemos chamar de ensino híbrido ${ }^{3}$. Vale dizer que não é meta das metodologias ativas de

\footnotetext{
${ }^{1}$ Ao falar na nova geração que frequenta o ensino médio (em idade regular), refere-se à "Geração Z" (BERNERS LEE, 1990 apud SAVAGE, 2006), crianças e jovens entre sete e dezoito anos.

${ }^{2}$ A premissa da teoria acadêmica prioriza a transmissão de conhecimentos sólidos e indiscutíveis, que tenham sido provados pelo tempo, sendo dividida em tradicional e generalista (BERTRAND, 2001).

${ }_{3}^{3}$ Horn et al (2015) entendem que se trata de qualquer programa educacional no qual o aluno estuda em casa, de forma autônoma, a partir da auto supervisão, controlando seu ritmo de 
aprendizagem, nem das TDIC, a extinção da escola dita tradicional, mas a abertura de seus espaços para uma interconexão com a cultura digital, superando abordagens que centram-se apenas na fala do professor, na leitura do livro e na passividade do estudante, que geralmente só responde ao que Ihe foi solicitado (ALMEIDA, 2018).

$O$ artigo em tela tem a seguinte estrutura: o primeiro item, "Aprendizagem além da cultura da sala de aula tradicional, o segundo, "Geração $Z$ e suas especificidades educativas" o item três, "Do ensino tradicional às metodologias ativas de aprendizagem", o quarto item, "Exemplos de metodologias ativas", por fim, o último: "Aprendizado ativo no contexto da EPT".

\section{APRENDIZAGEM ALÉM DA CULTURA DA SALA DE AULA TRADICIONAL}

É sabido que a sala de aula não é mais o único espaço onde o conhecimento se reproduz. É perpectível também que o aluno almeja participar de aulas que estejam em consonância com a realidade tecnológica que o cerca. Não é difícil, por exemplo, encontrar um aluno que, tendo um celular, com ou sem acesso à internet, não faça uso dele durante a aula, indepedente da autorização docente. O professor também não é mais a única fonte de conhecimento (como o modelo tradicional propunha), passando a existir modelos de ensino on-line e híbridos.

Face a tantas mudanças tecnológicas e digitais, o professor precisa trabalhar de maneira empenhada no sentido de despertar o interesse do aluno na sala e fora dela. Isso exige uma atenção maior ao perfil dos estudantes, bem como a geração de alunos que ele está mantendo contato em sala de aula. É preciso que haja respeito aos valores trazidos pelos discentes, por suas tendências educacionais, a fim de promover uma melhor interação na relação dodiscente ${ }^{4}$. Faz-se importante frisar que não se tem a intenção de culpabilizar o professor, mas apoia-lo, compreendendo que ele está inserido num espaço que exige habilidades, permeado por no mínimo duas gerações diferentes no que tange às influências midiáticas, sendo que não o prepararam para esse desafio em seu cotidiano (ALMEIDA, 2018).

A discussão sobre o uso das tecnologias vai além de sua inserção na sala de aula. Ainda se tem a ideia das tecnologias somente como uma possibilidade de fuga da aula convencional, buscada apenas como uma distração para o aluno. Outrossim, para os que abraçam as ferramentas

estudo, com recursos online, e outra parte na escola, sob a supervisão docente, característico do ensino presencial.

${ }^{4}$ Dodiscência (FREIRE, 2013) é o compartilhamento de experiências individuais e sociais entre 0 docente e o discente para a apreensão de saberes, na busca de conhecimentos históricos, políticos, culturais e sociais que avultem a consciência e a responsabilidade de todos perante a vida. 
tecnológicas, não basta inserir a tecnologia e manter a aula tradicional, é preciso fazer uso dos recursos tecnológicos, todavia, alterar também a cultura de sala de aula.

A forma comumente usada na maioria das salas de aulas brasileiras, priorizando a transmissão de conhecimento, sendo conteudista e verticalizada, funcionou durante muito tempo, porém, hoje, será que atinge os mesmos objetivos? Moran responde dizendo que "os métodos tradicionais, que privilegiam a transmissão de informações pelos professores, faziam sentido quando o acesso à informação era difícil" (MORAN, 2015, p.16). Nesse contexto, surgem as possíveis dificuldades dos professores que foram formados a partir de um ensino estritamente tradicional, em abrir mão de sua autoridade e em acompanhar e formar o aluno "nativo digital" (PALFREY e GASSER, 2011). Estes últimos, envolvidos com as tecnologias, (denominados geração $Z$ ), não aprendem da mesma maneira que seus professores (gerações $\mathrm{X}$ e $\mathrm{Y}$ ) aprenderam, e se conseguem êxito, a grosso modo, é com certeza a muito custo, sem muito envolvimento e com pouca satisfação.

\section{GERAÇÃO Z E SUAS ESPECIFICIDADES ECUCATIVAS}

A Geração Z, nascida após 1990, junto com o sistema de hiperlinks "WWW" diz respeito a crianças e jovens, dos sete aos dezoito anos. A letra $Z$ vem do termo inglês zapping que se traduz em dar uma volta; tendo ligação com a palavra zapear, trocar de canais de televisão, acessar a internet, vídeos, celulares, entre outros recursos digitais. Eles se caracterizam por ter compreensão das TDIC, por exercerem muitas tarefas ao mesmo tempo, por serem abertos às redes sociais, por serem rápidos (todavia, impacientes) e por sua resiliência (FEIXA; LECARDI, 2010).

A nova demanda de alunos está cercada de distrações convidativas. Como afirma Matos (2018, p. 19), a partir de um exemplo fora do contexto da sala de aula, mas que pode ser análogo à ele, "Façam um exercício mental e verifique em uma reunião de trabalho, por exemplo: Por quanto tempo a pessoa que conduz a reunião consegue a atenção de todos sem que alguém confira alguma vez o celular?". A resposta com certeza é por pouco tempo. Dessa maneira, como um professor pretende prender a atenção do aluno contemporâneo, em vista de uma oralidade que parece não ter fim durante todo o tempo de aula?

É comum perceber na Geração Z, atividades simultâneas: televisão e celular, celular e livro, escrever e ouvir música. Essas são algumas de suas características, levadas para a vida acadêmica e profissional. De acordo com

\footnotetext{
${ }^{5}$ Nativo digital diz respeito aquele que nasceu e cresceu cercado de novas tecnologias, como videogames, celulares, internet, etc.

${ }^{6}$ De World Wide Web, criado por Tim Berners-Lee em 1990 e divulgado em 1991.

Vol. 1 (2020)
} 
Costa (2015), existe um espanto docente, que por vezes, não compreende como essa nova geração consegue ler, ouvir música, estar online numa conversa com um amigo, tudo ao mesmo tempo. Vale dizer que essa geração já nasceu com a chegada da internet e o desenvolvimento das tecnologias, sendo esses recursos próximos à maioria deles.

É importante salientar também que a voz do professor não soa mais com tanta força, como em outros momentos: "A geração da internet tem mil amigos no Facebook, 500 seguidores do Twitter. O professor é só uma referência entre outras muitas que eles têm" (CHERUBIN, 2012, p. 12). Considerando os avanços tecnológicos e os alunos das gerações $Z$, as metodologias ativas de aprendizagem surgem como uma possibilidade, mediando o uso de ferramentas do que fazem parte do mundo dos alunos: celulares, redes sociais, aplicativos, games, entre outros. A geração baby boomers e as gerações $\mathrm{X}, \mathrm{Y}$ (geralmente os professores de hoje), Z, e Alpha (os alunos de hoje), foram definidas em função da evolução da informática como instrumento de aprendizagem. A tabela a seguir detalha a faixa etária de cada uma delas:

Quadro 1: Gerações

\begin{tabular}{|c|c|c|c|c|}
\hline $\begin{array}{c}\text { Baby } \\
\text { Boomers }\end{array}$ & $\mathbf{X}$ & $\mathbf{Y}$ & Z & Alpha \\
\hline $\begin{array}{c}\text { Nascidos entre } \\
1945 \text { a } 1960 ; \\
\text { Têm } 59 \text { anos } \\
\text { ou mais }\end{array}$ & $\begin{array}{c}\text { Nascidos entre } \\
\text { 1961 a 1982; } \\
\text { De } \mathbf{3 7} \text { a } 58 \text { anos }\end{array}$ & $\begin{array}{c}\text { Nascidos entre } \\
1983 \text { e } 1997 ; \\
\text { De } 22 \text { a } 36 \\
\text { anos }\end{array}$ & $\begin{array}{c}\text { Nascidos entre } \\
1998 \text { e 2009; } \\
\text { De } 10 \text { a } 21 \\
\text { anos }\end{array}$ & $\begin{array}{c}\text { Nascidos após } \\
2010 ; \\
\text { De } \mathbf{0} \text { a } \mathbf{9} \text { anos }\end{array}$ \\
\hline $\begin{array}{l}\text { Nome dado } \\
\text { devido à alta } \\
\text { taxa de } \\
\text { natalidade } \\
\text { percebida nos } \\
\text { EUA, no pós } \\
\text { guerra }\end{array}$ & $\begin{array}{c}\text { Denominação } \\
\text { baseada no livro } \\
\text { de Douglas } \\
\text { Coupeland, Geraç } \\
\text { ão X: Contos para } \\
\text { uma cultura } \\
\text { acelerada. }\end{array}$ & $\begin{array}{c}\text { O nome } \\
\text { Geração Y foi } \\
\text { usado } \\
\text { inicialmente } \\
\text { pela antiga } \\
\text { União } \\
\text { Soviética. }^{8} \\
\text { Ficou também } \\
\text { conhecida } \\
\text { como Geração } \\
\text { Next ou } \\
\text { Millennnials. }\end{array}$ & $\begin{array}{c}\text { O termo surgiu } \\
\text { em 1998, a } \\
\text { partir da criação } \\
\text { da Wolrd Wide } \\
\text { Web } \\
\text { (www), por Tim } \\
\text { Berners-Lees, } \\
\text { no "boom" da } \\
\text { criação de } \\
\text { aparelhos } \\
\text { tecnológicos } \\
\text { modernos. }\end{array}$ & $\begin{array}{c}\text { Termo usado } \\
\text { pelo } \\
\text { australiano } \\
\text { Mark } \\
\text { McCrindle, } \\
\text { para designar } \\
\text { a nova geração } \\
\text { de crianças. }\end{array}$ \\
\hline
\end{tabular}

Fonte: 0 autor, baseado nas referências citadas

\footnotetext{
${ }^{7}$ Quando os soldados retornaram da guerra, houve a necessidade de mais pessoas para contribuir na reconstrução do estado (OLIVEIRA, 2010).

${ }^{8}$ De acordo com Oliveira, quando a antiga União Soviética exercia forte influência sobre países de origem comunista, chegava a definir a primeira letra dos nomes que deveriam ser dados aos bebês nascidos em determinado período. Nos anos de 1980 a letra principal era Y. Apesar disso não ter muita influência no mundo ocidental e capitalista, posteriormente muitos estudiosos adotaram esta letra para designar os jovens nascidos nesse período (OLIVEIRA, 2010).

Físico britânico, cientista da computação, professor e criador da World Wide Web. Conhecido como o "pai da Internet" por fazer a primeira comunicação bem-sucedida entre cliente e servidor via HTTP em 1998. (GRECO, 2010)
} 
O que precisa ficar muito claro é que a geração $Z$ não é mais inteligente que a geração $X$ ou $Y$, por exemplo, mas os recursos hoje disponíveis para ensinamentos são mais amplos e diversificados. Todavia, se não soubermos usar os recursos, mediando os discentes no processo de ensinoaprendizagem, as tecnologias, por si só, não alcançarão os resultados desejados. Tablets, smartphones, notebooks e outros instrumentos tecnológicos são recursos apenas, carecendo da orientação docente. $O$ Objetivo é que a escola perceba esses instrumentos como aliados, ao invés de afastá-los de suas práticas educativas, considerando principalmente que a escola, composta por gerações diferentes, tem o dever de ser democrática no que tange ao processo de ensino-aprendizagem, e não, de maneira impositiva, apresente um cardápio único para todos os aprendizes.

Quando falamos em metodologias ativas e tecnologias, não se quer com isso diminuir a importância do professor, mas tirar o aluno da passividade que Ihe foi imposta. Todavia, vale dizer que as metodologias ativas, as TDIC, internet e modernidade do nosso aluno carecem da mediação docente. 0 professor não deve sair de cena, mas ocupar um lugar que permita que o aluno tenha espaço. No modelo tradicional, hegemônico em nosso país, concebido sobretudo na revolução industrial ${ }^{10}$, "O professor 'dá a lição', imprime-a em arquivadores do conhecimento e pede, em troca, que os alunos usem a sua atividade mental para acumular, armazenar e reproduzir informações" (SANTOS; PRAIA, 1992, p. 13 apud VASCONCELOS; PRAIA; ALMEIDA, 2003, p. 12). Objetiva-se que esse cenário se altere.

Contrário ao modelo conteudista, pretende-se constituir um novo saber, a partir de um formato de educação que atenda às necessidades da contemporaneidade. Bergmann e Sams (2016), afirmam que alguns alunos precisam ser motivados quanto ao material, considerando que não se interessam pelo assunto ou não se sentem atraídos pelo modelo educacional apresentado. Nesse sentido, tem-se como possibilidade as metodologias ativas de aprendizagem, atrelado a inúmeras possibilidades tecnológicas que conversam com o aluno nativo digital.

\section{DO ENSINO TRADICIONAL ÀS METOdOLOGIAS ATIVAS DE APRENDIZAGEM}

Além do modelo tradicional de ensino, existem outras abordagens. Saviani (2011) nos aponta que a educação no Brasil passou por quatro grandes momentos: predomínio da pedagogia tradicional religiosa (15491759); pedagogia tradicional laica, numa disputa com a tradicional religiosa

\footnotetext{
${ }^{10}$ De acordo com Bergmann e Sams (2016, p. 6), “[...] os alunos são educados como em linha de montagem, para tornar eficiente a educação padronizada. Sentam-se em fileiras de carteiras bem arrumadas, devem ouvir um especialista na exposição de um tema e ainda precisam lembrar das informações recebidas em um teste avaliativo".
} 
(1759-1932), pedagogia nova (1932-1969), marcado pela ideia renovadoras; e por último e pedagogia produtivista (1961-2001), marcado pelo domínio do capital humano. A escola tradicional, precede a Escola Nova, sendo que após esses dois nortes metodológicos, surgem outros, tais como a escola libertadora, a tecnicista, e por último a histórico-crítica. Segundo Araújo (2015, p. 1), "existem expectativas e aspirações, [...] de que as orientações tradicional, escolanovista e tecnicista tivessem sido efetivamente superadas teórica e praticamente, porém elas são revigoradas por estruturas e situações pedagógicas e didáticas diversas [...]. As metodologias ativas, por exemplo, são consideradas uma marca escolanovista, centrada na aprendizagem, no aluno, tornando-o protagonista, retirando o professor do pedestal em que 0 currículo tradicional o colocou.

A escola tem sido desafiada a integrar efetivamente as tecnologias digitais na educação. De forma bastante rápida, as TDIC tem entrado na sociedade, e tem um papel importantíssimo no contexto da educação. $O$ aluno que tem acesso às informações por elas proporcionadas, podendo se apropriar de inúmeros conteúdos. Essa é uma novidade do nosso tempo, visto que historicamente, o professor era o detentor dessas informações, e se o aluno quisesse se apropriar antes, deveria se esforçar através de meios mais exaustivos de pesquisa. Em suma, o acesso era muito diferente do hodierno. Ocorre que hoje, os alunos podem chegar às informações antes do docente, e de acordo com Bacich, Tanzi Neto e Trevisani (2015) muitos professores ainda não detêm o conhecimento necessário para a utilização de ferramentas e tecnologias da atualidade em seu ensino, o que não significa dizer que não há esforço investido pela parte docente. Conclui-se, segundo Pereira e Lima (2018) que os professores precisam mudar a forma de ensinar, assim como os alunos precisam assumir novos papéis dentro e fora da sala de aula.

\section{EXEMPLOS DE METODOLOGIAS ATIVAS DE APRENDIZAGEM}

A busca por instrumentos educacionais eficientes, os quais objetivam introduzir dinamismo e ao mesmo tempo qualidade na transmissão de conhecimento, enfatiza a importância das metodologias ativas e das TDIC. Sendo assim, baseado nessa premissa, propomos o artigo em tela. Utilizar o tempo de aula somente para a oralidade, no qual o aluno age de forma passiva, não é mais tão eficiente. Diante da necessidade de uma atuação mais ativa por parte dos discentes, surgem as metodologias ativas de aprendizagem.

A escola há de mudar para contribuir para a construção desse outro mundo possível. A sociedade, os pais, os professores devem aliviar a pressão hoje exercida sobre os jovens, desapertar os parafusos de uma máquina escolar que, atualmente, machuca por demais os alunos, inclusive os "bons". A lógica da concorrência deve ser substituída pela lógica da excelência, democrática, desde que se 
considere a variedade das formas de excelência. A lógica do armazenamento solitário de informações deve ceder o lugar à da reflexão, da invenção, do trabalho em equipe, o que, aliás, a Internet possibilita e a sociedade globalizada pede. É preciso, ainda, que a escola assuma o fato de que, hoje em dia, ela é o principal lugar de socialização da juventude, e repense a vida juvenil na escola. (CHARLOT, 2014, p. 126)

Apesar de parecer uma discussão recente, as MA não são uma novidade na educação. Trevelin et al (2013), Teixeira (2013) e Valente (2014) confirmam, ao datar os primeiros passos das metodologias ativas desde a década de 90. A novidade se dá pela maneira como hoje, pode-se trazer para a sala de aula essas metodologias, através das TDIC, aplicativos, considerando o perfil do aluno do século XXI.

De acordo com Suhr (2016, p. 6)

[...] podemos afirmar que esta organização prevê o uso intensivo das TICs para a transmissão dos conceitos ao aluno, dando espaço para que nas aulas propriamente ditas o professor possa utilizar atividades mais interativas, que desenvolvam habilidades de raciocínio mais complexas. O material instrucional criado pelo professor é disponibilizado aos alunos de diversas maneiras: tutoriais, roteiros de estudo, teleaulas, indicações de leitura, etc. Em todos os casos citados, trata-se de material elaborado especificamente para este fim e aos quais o aluno acessa por meio de plataformas de ensino também conhecidas como ambientes virtuais de aprendizagem (AVAs).

Ao usar uma videoaula do Youtube EDU, por exemplo, como antecipação de conteúdo, característica da metodologia ativa chamada sala de aula invertida, cria-se a possibilidade de otimização do tempo em sala de aula. De acordo com Ganood et al (2008), ouvir as explicações passa a ser uma atividade autônoma do aluno, orientado pelo professor, mas fora de sala de aula. O tempo que seria gasto com a transmissão de informações, passa a ser de engajamento entre professor e aluno. Há aqui uma economia de tempo para ambos, pois, o que seria gasto com a oralidade docente pode ser usado na promoção de um aprendizado significativo, no processo de avaliação, na personalização do ensino (foco às necessidades individuais dos discentes), no esclarecimento de dúvidas, etc. Conteúdo antecipado, bem como, uma menor quantidade de apresentação passiva de conteúdo é o cerne da sala de aula invertida.

No que diz respeito às tendências pedagógicas que envolvem a proposta de sala de aula invertida, podemos trazer como suporte a progressista libertadora. Proposta por Paulo Freire, ele enfatiza que os espaços de produção de conhecimento perpassam as quatro paredes da sala de aula, podendo ser administrada em outros espaços da unidade de ensino, 
quiçá, além muros. No mundo pós-moderno, cercado pelas TDIC, essa ideia é reforçada pelo crescente número de informações que circulam via internet, redes sociais, plataformas de produção de conhecimento, ou seja, nem a escola é a única fonte de conhecimento, assim como o professor deixa de ser a única fonte de consulta.

Relaciona-se com o humanismo, proposto por Carl Rogers, autor desse enfoque teórico de aprendizagem, expressando as ideias básicas do: aprender a aprender, liberdade para aprender, ensino centrado no aluno e crescimento pessoal. $\mathrm{O}$ autor defende que $\mathrm{o}$ aluno precisa tomar consciência de suas necessidades, autodirigir a sua aprendizagem (significativa), desenvolver autonomia, carecendo de liberdade para vivenciar esse processo (MOREIRA, 2011). Partindo para o lado comumente dotado de poder, o docente passa a ser mediador, não ensina de forma autoritária, mas promove a facilitação da aprendizagem, criando um clima sem censuras e controle.

As Metodologias Ativas (MA) tendem a promover um aluno interessado pelos seus estudos. O estudante é corresponsável por seu processo de formação, autor da sua própria aprendizagem. Valente (2014) compactua com a mesma ideia, entendendo que na aprendizagem ativa, ao contrário do que acontece na aprendizagem passiva, que Paulo Freire (2013) chama de educação bancária ${ }^{11}$, baseada somente na transmissão de informação, 0 aluno ativo assume uma postura de ação, resolvendo problemas, desenvolvendo projetos e criando oportunidades para a construção de conhecimento. Essas são características de outro tipo de metodologia ativa: A PBL (Aprendizagem baseada em problemas). Nesse cenário o professor terá a função de orientar, motivar e facilitar a ação educativa.

Bastos (2006) entende como MA os "processos interativos de conhecimento, análise, estudos, pesquisas e decisões individuais ou coletivas, com a finalidade de encontrar soluções para um problema." Partindo dessa premissa, o professor deixa de ser a personagem principal, passando a ser mediador, motivando o estudante a desenvolver 0 autogerenciamento, mirando em metas para atingir seus objetivos.

Além das duas maneiras anteriormente citadas, existem hoje inúmeras possibilidades de MA, para favorecer a ação educativa discente, conforme figura 1.

\footnotetext{
${ }^{11}$ Freire (2013) propunha uma prática de sala de aula que pudesse desenvolver a criticidade dos alunos e condenava o tradicionalismo da escola brasileira, que chamou de educação bancária, em que o professor deposita o conhecimento no aluno.
} 
Figura 1 - Possibilidades de Metodologias Ativas

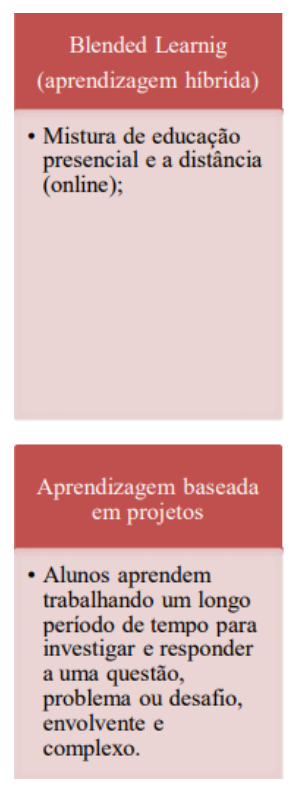

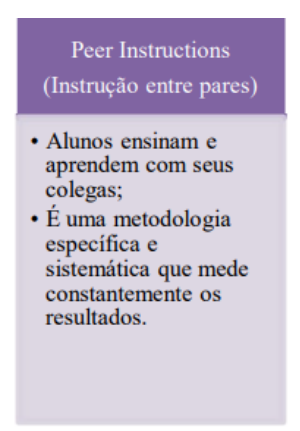

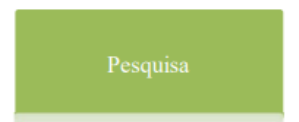

- Produção de trabalhos para disciplinas, iniciação científica ou Trabalhos de

Conclusão de Curso (TCC), onde o professor atua como orientador.

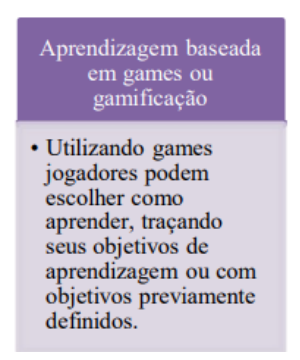

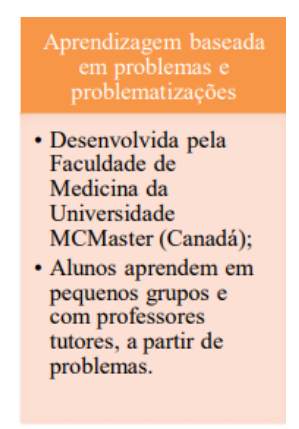

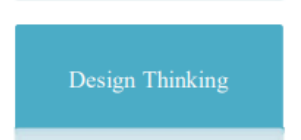

- Propõe soluções criativas e inovadoras para problemas que pensar dos designers.

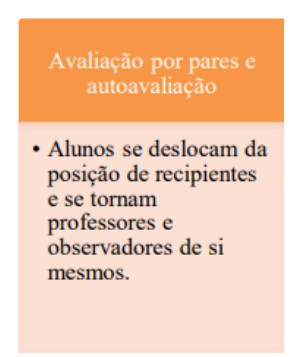

Fonte: Mattar (2017)

Retomando o exemplo da sala de aula invertida (do inglês Flipped Classroom), o aluno estuda o assunto antes da aula, através de materiais indicados pelo professor. Após estudar o conteúdo em casa, no seu ritmo, à sua maneira, o professor traz exercícios para o encontro presencial, retrabalhando o conteúdo com o aluno. A aula invertida foi criada em 2007, pelos professores Bergmann e Sams (2016), nos Estados Unidos. Após um ano de experiência ministrando aulas de química, constataram a eficácia dessa prática, que tornava a aula mais dinâmica e personalizada. Os autores afirmam ainda que inverter a sala de aula é fazer em casa o que era feito em aula, ou seja, em casa assistem-se palestras, vídeos, ou se apropriam de algum outro material indicado pelo professor e, em sala, resolve-se problemas, solucionam-se as dúvidas advindas desse primeiro estudo (BERGMANN e SAMS, 2016).

O que era feito em sala no modelo tradicional de ensino (recepção de conteúdo), passa a ser feito em casa, de controle e medição do próprio aprendiz. Conforme sinaliza Horn e Staker (2015), nesse modelo, os alunos participam de momentos on-line, apresentados virtualmente aos conteúdos expositivos, assumindo a responsabilidade pelo estudo teórico, sendo que a aula presencial servirá para aplicar, de forma prática, aquilo que previamente foi estudado de maneira autônoma.

$\mathrm{Na}$ Instrução pelos pares ou Peer Instruction, outro exemplo de metodologia ativa, os alunos estudam sozinhos antes da aula, materiais indicados pelo professor, se assemelhando com a sala de aula invertida, podendo inclusive ser utilizada conjuntamente. A aula começa com uma pequena exposição e o professor apresenta uma questão de múltipla escolha, 
dando alguns minutos para o aluno responder individualmente. Caso uma parte considerável erre a questão, o professor reúne grupos para que os alunos tentem convencer uns aos outros de suas respostas. Após a reunião de ideias, o professor faz um novo levantamento das respostas, e caso eles tenham entrando num consenso, e a maioria dessa vez tenha acertado, o professor explica a resposta correta, tirando as possíveis dúvidas dos alunos.

Esse método foi desenvolvido pelo professor de física Eric Mazur (MAZUR, 2015), na década de 90, em Havard, quando percebeu que os alunos sabiam resolver os problemas propostos pela disciplina, mas não aprendiam de maneira satisfatória. Dessa maneira, ele optou pela mudança em sua maneira de ensinar, incluindo tecnologias, gerando interatividade e colaboração entre os pares, ultrapassando os limites tradicionais da sala de aula.

\title{
6 APRENDIZADO ATIVO NO CONTEXTO DA EPT
}

A sociedade tem feito a exigência de cidadãos críticos, que saibam enfrentar problemas e situações adversas. Diante disso, existe a necessidade de aplicação dos conhecimentos de uma maneira nova, não sendo satisfatório apenas o "saber que" (saber teórico), mas este vinculado ao "saber como" (saber técnico), numa relação que aprimore a educação (Barato, 2008). A partir dessa premissa, o aluno do século XXI, cercado por transformações fundamentadas nas TDIC, precisa estar preparado a resolver problemas, a agir diante do inesperado, ser ativo, e conforme afirma Libâneo (2001)

\begin{abstract}
Essas transformações tecnológicas e científicas levam à introdução, no processo produtivo, de novos sistemas de organização do trabalho, mudança no perfil profissional e novas exigências de qualificação dos trabalhadores, o que acaba afetando o sistema de ensino. [...] De fato, com a "intelectualização" do processo produtivo, o trabalhador não pode mais ser improvisado. São requeridas novas habilidades, mais capacidade de abstração, de atenção, um comportamento profissional mais flexível. Para tanto, a necessidade de formação geral se repõe, implicando reavaliação dos processos de aprendizagem, familiarização com os meios de comunicação e com a informática, desenvolvimento de competências comunicativas, de capacidades criativas para análise de situações novas e cambiantes, capacidade de pensar e agir com horizontes mais amplos. (LIBÂNEO, 2001, p.5)
\end{abstract}

É relevante a necessidade de adequação no que tange às várias transformações sociais e tecnológicas, tendo os indivíduos que se adequarem a elas, dando um retorno sempre positivo quando o assunto é o uso das TDIC. "Espera-se que os egressos da Educação Profissional e Tecnológica (EPT) sejam capazes de transitar com desenvoltura e segurança em um 
mundo cada vez mais complexo e repleto de tecnologias inovadoras" (BARBOSA; MOURA, p. 50). O autor completa:

\begin{abstract}
Podemos dizer que a EPT requer uma aprendizagem significativa, contextualizada, orientada para o uso das TIC, que favoreça o uso intensivo dos recursos da inteligência, e que gere habilidades em resolver problemas e conduzir projetos nos diversos segmentos do setor produtivo. Como contraponto, podemos dizer que a aprendizagem em EPT deve estar cada vez mais distante da aprendizagem tradicional, fundamentada no poder do verbo, teórica e dependente do uso intensivo da memória.
\end{abstract}

Para tornar o aluno um agente ativo em sua aprendizagem, novas tendências e metodologias fazem-se necessárias, sendo a formação docente de essencial importância. A própria LDB 9394/96, em seu artigo 36 da LDB, orienta que o currículo do Ensino Médio adote metodologias de ensino e de avaliação que estimulem a iniciativa dos estudantes. Apesar disso, vivemos um modelo tradicional majoritário, consequência da teoria acadêmica norteadora da educação brasileira.

Conforme Charlot (2008) as práticas pedagógicas brasileiras são basicamente tradicionais e o professor tem de enfrentar uma dupla contradição. Eles tentam basear sua prática entre a abordagem tradicional e a construtivista, mas o que se sobressai, de fato, são as práticas tradicionais: expressão e desenho livres; debates na sala, inclusive "debate científico"; momentos de trabalho em grupo, de pesquisa coletiva, com base em documentos ou na Internet etc.

A EPT tem sido objeto de discussões, com destaque, o currículo e percursos formativos no que tange à formação de competências profissionais. A partir de metodologias ativas, as práticas puramente tradicionais de ensino são refletidas, abrindo-se às inúmeras possibilidades de metodologias ativas de aprendizagem. Considerando as especificidades da Educação Profissional e Tecnológica, as metodologias ativas se coadunam, no sentido de superar o modelo tradicional, a partir de práticas docentes inovadoras no contexto da formação profissional. Lisboa e Santos (2013) apontam que os alunos, futuros profissionais, estão em busca de autonomia, tendendo a recuar perante qualquer ato de autoridade vertical, ou seja, não apresentam características de passividade.

Para tanto, questiona-se: o educador da EPT tem conseguido suprir os anseios do aluno da geração $Z$ trabalhando somente com o modo tradicional de transmitir conhecimento? A transmissão de conteúdo tem alcançado os objetivos da aprendizagem? E a premissa da educação é somente transmitir conhecimentos? Para Mészarós (2008), não é, mas gerar conscientização e testemunho de vida, sendo que a aprendizagem é a nossa própria vida. Ramos (2017) complementa:

[...] passamos pelo tempo da pedagogia tradicional, em que a finalidade da educação era transmitir às novas gerações a tradição de um grupo social num dado tempo. Essa foi, fortemente, criticada 
pela pedagogia nova, inspirada no pensamento de John Dewey, já no contexto da produção industrial, em que a capacidade de pensar, cientificamente, torna-se uma necessidade desse novo tempo. (RAMOS, 2017, p. 26)

Hoje os alunos são constantemente influenciados pela internet, pelas redes sociais, enfim, pelas TDIC. Moran, Masetto e Behrens (2013) falam da rapidez desses instrumentos como recursos de comunicação, pesquisa e descoberta, que nos permite viver novas e inúmeras experiências, tendo o ferramental tecnológico como meio de facilitação. Assim, insistir numa educação enraizada na abordagem tradicional, em que o professor é o centro e a oralidade do mesmo é ponto forte das relações em sala de aula, contradiz com a formação integral e politécnica proposta pela EPT. Partindo desse pressuposto, a educação deve ser fonte de colaboração no processo de ensino-aprendizagem. De acordo com Vygotsky (2001), aprender em colaboração é um processo complexo de atividades sociais, motivado por interações mediadas pelas relações entre alunos, professores e sociedade.

O aluno, ao buscar autonomia em sala de aula, almeja tornar-se agente ativo do seu processo de ensino e aprendizagem, cenário bem diferente da realidade posta atualmente. Para Charlot (2014, p. 53, grifo nosso)

[...] eles vão à escola para, antes de tudo, tirar notas boas e passar de ano e, ademais, consideram que é a professora quem é ativa no ato de ensino-aprendizagem. Quanto maior a pressão exercida pela nota, mais os alunos desenvolvem estratégias de sobrevivência: frear o professor, colar, decorar os conteúdos sem entendê-los etc. Isso não significa que os alunos sejam idiotas ou não gostem de refletir; significa, sim, que tentam sobreviver em uma escola que os coloca em situações que contradizem os objetivos de espírito crítico e autonomia proclamados por ela. Em uma situação dessas, os momentos construtivistas constituem conquistas da professora, conforme a inteligência epistemológica e pedagógica, mas à contracorrente da ordem socioinstitucional da escola contemporânea.

A inserção de metodologias ativas nas práticas educativas diz muito da realidade do aluno hodierno. A relação delas com as TDIC possibilita aos usuários ter acesso aos mais variados conteúdos, disponibilizados ou não pelos professores, gerando novas oportunidades de aprendizado. Segundo Valente "metodologias ativas constituem alternativas pedagógicas que colocam o foco do processo de ensino e de aprendizagem no aprendiz, envolvendo-o na aprendizagem por descoberta, investigação ou resolução de problemas" (VALENTE, 2018, p. 27). Por esse motivo, podemos dizer que as metodologias ativas de aprendizagem se centram no aluno, deixando de protagonizar o professor. 
Apesar de parecer algo novo, as metodologias ativas de aprendizagem surgem com a Escola Nova ${ }^{12}$, entre o final do século XIX e início do século $X X$, na Inglaterra, tendo como objetivo principal a superação do tradicionalismo nas escolas. É preciso pensar uma educação problematizadora, partindo da realidade de alunos pensantes, visto que, a vivência dos estudantes é a fonte primária na construção do currículo (Freire, 2013).

Moran (2007) alerta para a necessidade de estabelecer contato entre professores e os meios de comunicação, para que, por sua vez, estes compreendam o processo de troca que é a educação, ambos entendendo o seu significado dentro da sociedade, ajudando na democratização e exercício da cidadania. Enquanto a pedagogia dos conteúdos está estritamente preocupada em inserir da mente do alunado uma gama de conceitos e informações, não havendo aqui um uma interação entre educador/educando, a nossa preocupação é desmistificar a ideia que diz que o mestre é o detentor do conhecimento e que o aluno precisar abrir a cabeça vazia para receber uma dosagem de conhecimento que somente o professor poderá depositar.

Pretende-se promover uma aprendizagem ativa, na qual o aluno possa interagir com o conteúdo estudado, ouvindo, mas também falando, perguntando, debatendo, discutindo, fazendo, ensinando, sendo estimulado a construir conhecimento, deixando de ser um agente passivo em sua aprendizagem (BARBOSA E MOURA, 2013). A transformação de práticas de ensino tradicionais e a inserção de novos modos de aprendizado, intui principalmente em reconfigurar a educação, a partir de uma metodologia ativa, dando subsídio para o romper com a passividade.

\section{CONSIDERAÇÕES FINAIS}

Como dito nesse artigo, a maneira tradicional de ensinar, centrada na figura do professor, não é uma metodologia apropriada para a geração Z. Há um grande potencial desperdiçado em nossas escolas, em vista de ideias educacionais obsoletas. [...] É uma tragédia ver, a cada dia, milhares de alunos sendo convencidos de que são incapazes e pouco inteligentes simplesmente porque não conseguem se adaptar a um sistema equivocado (BLIKSTEIN, 2010, p. 3).

Esse tipo de processo burla a autonomia discente. Essa situação é ratificada ao fazermos uma breve análise da abordagem usada na maioria das escolas brasileiras, na qual não há participação discente e o professor ainda "dita as regras" em sala de aula, o aluno passa horas e horas sentado passivamente, recebendo informações. Essa geração não corresponde

\footnotetext{
${ }^{12}$ A Escola Nova, chamada também de Escola Ativa, trata-se de um movimento de buscou a superação do ensino tradicional. Iniciada na Europa pelo suíço Ferrière, chega ao Brasil em 1920.
} 
avidamente ao ensino unilateral, mas tem mostrado a necessidade por metodologias ativas de aprendizagem, principalmente através das TDIC. De acordo com Castanha e Castro (2010) esta seria a "nova educação", transformando o lugar da reprodução passiva de informações já existentes, almejando-se cada vez mais o estímulo à criatividade dos estudantes.

Assim, concluímos esse trabalho reafirmando que cada geração tem um perfil, cada aluno tem sua forma de aprender. Somente esses aspectos seriam de grande relevância para motivar o professor e a escola na mudança de cultura de sala de aula. Assim, fica o grande desafio de revisão nas práticas educativas que não geram o protagonismo dos alunos e que abdicam ingenuamente das TDIC como aporte educacional, mesmo sendo ele direcionado para a geração que nasceu cercado por um mundo digital.

\section{REFERÊNCIAS}

BACICH, L.; TANZI NETO, A.; TREVISANI, F. M. (Org.). Ensino híbrido: personalização e tecnologia na educação. Porto Alegre: Penso, 2015.

BARATO, Jarbas Novelino. Conhecimento, trabalho e obra: uma proposta metodológica para a Educação Profissional. B. Téc. Senac: a R. Educ. Prof, v.34, n. 3, 2008. Disponível em:

http://www.bts.senac.br/index.php/bts/article/view/262/245. Acesso em: 21/01/2019

BARBOSA, Eduardo Fernandes; MOURA, Dácio Guimarães de. Metodologias ativas de aprendizagem na educação profissional e tecnológica. B. Tec. Senac, Rio de Janeiro, v. 39, n.2, p.48-67, maio/ago. 2013. Disponível em: http://www.bts.senac.br/index.php/bts/article/view/349. Acesso em: 21/03/2019

BASTOS, C. C. Metodologias ativas. 2006. Disponível em: http://educacaoemedicina.blogspot.com/ 14 fev. 2010. Acesso em: 21/01/2019

BERGMANN, J.; SAMS, A. Sala de aula invertida: uma metodologia ativa de aprendizagem, 2016

BERTRAND, Yves. Teorias contemporâneas da educação. 2. ed. Lisboa: Instituto Piaget, 2001.

BLIKSTEIN, P. O mito do mau aluno e porque o Brasil pode ser o líder mundial de uma revolução educacional. 25 jul. 2010. Disponível em: http://www.blikstein.com/paulo/documents/books/ BliksteinBrasil_pode_ser_lider_mundial_em_educacao.pdf. Acesso em: 15 mar. 2019 BRASIL. Lei no 9.394, de 20 de dezembro de 1996. Estabelece as diretrizes e bases da educação nacional. DOU, Brasília, 23 dez. 1996. disponível em: www.planalto.gov.br/ccivil_03/leis/ I9394.htm. Acesso em: 20 fev. 2019. 
CHARLOT, Bernard. O professor na sociedade contemporânea: um trabalhador da contradição. Revista da Faeeba: Educação e Contemporaneidade, Salvador, v. 17, n. 30, p. 17-31, jul.-dez., 2008.Disponível em: http://www.uneb.br/revistadafaeeba/files/2011/05/numero30.pdf. Acesso em 20 jan. 2019.

CHARLOT, Bernard. Da relação com o saber às práticas educativas. São Paulo: Cortez, 2014.

CHERUBIN, Karina Gomes. Para lidar com a geração z, professores recorrem a redes sociais. Disponível em:

http://mpcidadania.ning.com/profiles/blogs/para-lidar-com-geracao-zprofessor-recorre-as-redes-sociais. Acesso em: 08 abr. 2019.

COUPLAND, Douglas. Geração X: contos para uma cultura acelerada. Lisboa: Teorema, 1994.

COSTA, C. O papel do docente hoje é fazer parceria com os alunos. Ensino Superior Campinas/SP, Unicamp, 2015.

FEIXA, Carles; LECCARDI, Carmen. O conceito de geração nas teorias sobre juventude. Sociedade e Estado, Brasília, DF, v. 25, n. 2, p. 185-204, maio/ ago. 2010. Disponível em: http://www.scielo. br/scielo.php?script=sci_a r t t e x t \& p i d = S 010 2- 69922010000200003 Acesso em: 30 abr. 2019.

FREIRE, Paulo. Pedagogia do oprimido. Rio de Janeiro: Paz e Terra, 2013. GRECO, Alessandro. A web 3.0: A internet vai dar um salto qualitativo com a web semântica. Revista BR, ano 2, n.2, 2010.

HORN, M. B.; STAKER, H. Blended: usando a inovação disruptiva para aprimorar a educação. Porto Alegre: Penso, 2015.

LIBÂNEO. Pedagogia e pedagogos: inquietações e buscas. Educar, Curitiba, n. 17, p.153-176, 2001. Disponível em: http://www.scielo.br/pdf/er/n17/n17a12.pdf. Acesso em: 04 mar 2019.

MATTAR, J. Metodologias Ativas: para a educação presencial, blended e a distância. São Paulo: Artesanato Educacional, 2017.

MATOS, Vinícius Costa. Sala de aula invertida: uma proposta de ensino e aprendizagem em matemática. 142 f. Dissertação (Mestrado Profissional em Matemática/PROFMAT). Universidade de Brasília, Brasília/DF, 2018.

MAZZUR, Eric. Peer Instruction: a revolução da aprendizagem ativa. Porto Alegre: Penso, 2015.

MÉSZÁROS, István. A educação para além do capital. 2. ed. São Paulo: Boitempo, 2008.

MORAN, J. M.; MASETTO, M. T; BEHRENS, M. A. Novas Tecnologias e mediação pedagógica. 21. ed. São Paulo: Papirus, 2013. 
MORAN, J. M. Mudando a educação com metodologias ativas. Coleção Mídias Contemporâneas. Convergência Midiáticas, Educação e Cidadania: aproximações jovens. v. 2, p. 15-33, 2015.

MORAN, J. M. Desafios na comunicação pessoal. 3. ed. São Paulo: Paulinas, 2007.

MOREIRA, M. A. Teorias de aprendizagem. 2. Ed. São Paulo: EPU, 2011.

PALFREY, John; GASSER, Urs. Nascidos na era digital: entendendo a primeira geração dos nativos digitais. Porto Alegre: Artmed, 2011.

PEREIRA, W. O.; LIMA, F. T. Desafio, discussão e respostas: estratégia ativa de ensino para transformar aulas expositivas em colaborativas, Einsten, São Paulo, n.16, v.2, p.1-4, 2018. Disponível em:

http://www.scielo.br/pdf/eins/v16n2/pt_1679-4508-eins-16-02-eED4362.pdf. Acesso em: 12 mar. 2019.

RAMOS, Marise N. Ensino médio integrado: lutas históricas e resistências em tempos de regressão. In.: ARAÚJJ, Adilson; SILVA, Cláudio Nei Nascimento da (Orgs.). Ensino Médio integrado no Brasil: fundamentos, práticas e desafios. Brasília/DF: Ed. IFB, 2017, p. 20-43.

SAVAGE, Sam. The generation $z$ connection: teaching information literacy to the newest net generation. RedOrbit, Nashville, 19 fev. 2006. Disponível em: http://www.redorbit.com/news/ technology/397034/the generation_z_connection_teaching_inforation_literacy_to_the_newest/. Acesso em: 30 abr. 2019

SAVIANI, Demerval. História das ideias pedagógicas no Brasil. 3.ed. Campinas/SP: Autores Associados, 2011.

SUHR, Inge Renate Frose. Desafios no uso da sala de aula invertida no ensino superior. Revista Transmutare, Curitiba, v. 1, n. 1, p. 4-21, jan./jun. 2016. Disponível em: https://periodicos.utfpr.edu.br/rtr/article/view/3872. Acesso em: 12 mar. 2019.

TEIXEIRA, G. P. Flipped classroom: um contributo para a aprendizagem da lírica camoniana. 2013. 167 f. Dissertação (Mestrado em Gestão de Sistemas de ELearning) - Faculdade de Ciências Sociais e Humanas, Universidade Nova Lisboa, Lisboa, 2013. Disponível em: http://run.unl.pt/bitstream/10362/11379/1/29841_Teixeira_FlippedClassroom_ LiricaCamoniana.pdf. Acesso em: 03 abr. 2019.

TREVELIN, A. T. C.; PEREIRA, M. A. A.; NETO, J. D. O. A utilização da sala de aula invertida em cursos superiores de tecnologia: comparação entre 0 modelo tradicional e o modelo invertido flipped classroom adaptado aos estilos de aprendizagem. Revista Estilos de Aprendizaje, Madrid, v. 11, n.12, 2013. Disponível em: https://www2.uned.es/revistaestilosdeaprendizaje/numero_12/articulos/articul o_8.pdf. Acesso em: 05 mar. 2019. 
VALENTE, José Armando. Blended Learning e as mudanças no Ensino Superior: a proposta da sala de aula invertida. Educar em Revista: Dossiê Educação a Distância, Curitiba: UFPR, Edição especial n. 4, p. 79-97, 2014. Disponível em: http://ojs.c3sl.ufpr.br/ojs2/index.php/educar. Acesso em: 12 mar. 2019.

VALENTE, José Armando. A comunicação e a educação baseada no uso das tecnologias digitais de informação e comunicação. Revista UNIFESO, v. 1, n. 1, 2014, pp. 141-166. Disponível em:

http://www.revista.unifeso.edu.br/index.php/revistaunifesohumanasesociais/ar ticle/view/17. Acesso em: 12 mar. 2019.

VASCONCELOS, Clara; PRAIA, João Félix; ALMEIDA, Leandro S. Teorias de Aprendizagem e o ensino/aprendizagem das ciências: da instrução à aprendizagem. Psicologia Escolar e Educacional, v. 7, n. 1, p. 11-19, jun. 2003. Disponível em: http://www.scielo.br/scielo.php?pid=S1413$85572003000100002 \&$ script=sci_abstract\&tlng=pt. Acesso em: 14 mar. 2019. VYGOTSKY, L. S. A construção do pensamento e da linguagem. São Paulo: Martins Fontes, 2001. 